\title{
Ergenlerin Sosyal Kaygı Düzeyleri ile Güvengenlik ve Özsaygıları Arasındaki İlişki
}

\author{
The Relationship between Assertiveness Self-Esteem and Social Anxiety of \\ Adolescent
}

Doç. Dr. Özlem TAGAY ${ }^{1}$, Dr. Öğr. Üyesi Özgür ÖNEN ${ }^{2}$, İbrahim CANPOLAT ${ }^{3}$

\begin{abstract}
Özet
Bireyler ihtiyaçlarını karşılarken sürekli iletişim ve etkileşim halindedir. Sağlıklı sosyal ilişkiler oluşturmanın önünde ciddi bir engel olan sosyal kaygı ise en basit şekilde bireyin olumsuz değerlendirilme korkusundan dolayı toplumsal ilişkilerinde sıkıntı yaşamasıdır. Sosyal kaygı özellikle ergenlik döneminin özelliklerinden dolayı ergenler arasında daha yaygın olabilmektedir. Güvengen ergenler kendilerini daha rahat ifade edebilirken çekingen olan ergenler kendilerini ifade edebilme konusunda sıkıntı yaşayabilmektedirler. Bu çalışmanın amacı ergenlerin sosyal kaygı düzeyleri ile güvengenlik ve öz-saygıları arasındaki ilişkiyi incelemektir. Araştırmanın çalışma grubunu yaşları 14 ile 18 arasında değişen 229 kadın (\%62) ve 140 erkek (\%38) olmak üzere toplam 369 lise öğrencisi oluşturmaktadır. Araştırmanın verileri Ergenler için Sosyal Kaygı Ölçeği, Kendini Belirleme (Güvengenlik) Ölçeği ve Coopersmith Öz-Saygı Envanteri ile elde edilmiştir. Araştırmanın yordanan değişkeni sosyal kaygı ve yordayan değişkenleri güvengenlik ve öz-saygı olarak belirlenmiştir. Elde edilen verilerin analizi için Pearson Momentler Çarpımı Korelasyon tekniği ve çoklu doğrusal regresyon analizi kullanılmıştır. Güvengenlik ve öz-saygı ergenlerin sosyal kaygılarının toplam varyansının \%42'ini açılamaktadır. Araştırma sonuçları incelendiğinde çekingenliğin ergenlerin sosyal kaygı düzeylerini pozitif yönde anlamlı düzeyde yordadığı ve öz-saygının ise ergenlerin sosyal kaygı düzeylerini negatif düzeyde anlamlı olarak yordadığı bulunmuştur. Bununla birlikte güvengenlik ergenlerin sosyal kaygılarını anlamlı düzeyde yordamamaktadır.
\end{abstract}

Anahtar sözcükler: Sosyal kaygı, güvengenlik, çekingenlik, öz-saygı, ergenler

\begin{abstract}
People get in social contact with each other all the time while satisfying their needs. Social anxiety, which is an important psychological barrier in social relations, by its simplest definition is having problem in social relations by the fear of experiencing negative evaluation of others. Social anxiety can be seen among adolescents more frequently because of the characteristics of the developmental period. At this period, assertive adolescents can express themselves better when compared by their shy counterparts. In this study, it was aimed to explain if adolescents' self-esteem, and assertiveness are the significant predictors of the social anxiety. Study group consists of 229 female (62\%) and 140 male $(38 \%)$ adolescents, in total 369 adolescents having secondary school education. Data was gathered by Social Anxiety Inventory for Adolescents, Assertiveness Inventory and Coopersmith

\footnotetext{
${ }^{1}$ Mehmet Akif Ersoy Üniversitesi, Eğitim Fakültesi, ozlemtagay@ gmail.com, Orcid ID: orcid.org /0000-0002-9821-5960

${ }^{2}$ Mehmet Akif Ersoy Üniversitesi, Eğitim Fakültesi, ozguronen@mehmetakif.edu.tr, Orcid ID: orcid.org/0000-0002-37157488

${ }^{3}$ Cumhuriyet Andolu Lisesi, ibrahimcanp@hotmail.com, Orcid ID:orcid.org/ 0000-0001-8346-1758
} 
Self-esteem Inventory. Criterion variable of the study is determined as social anxiety and predictor variables are determined as assertiveness and self-esteem. Data was analyzed by Pearson product moment correlation and linear regression methods. Assertiveness and self-esteem predicts the 42 per cent of the variance on social anxiety of the adolescents. Results indicate that shyness is a significant positive predictor of social anxiety while self-esteem is a significant negative predictor of social anxiety. However, it is found that assertiveness is not a significant predictor of social anxiety

Key words: Social anxiety, assertiveness, shyness, self-esteem, adolescents

\section{Giriş}

Ergenler günlük yaşamlarında sürekli iletişim ve etkileşim içerisindedirler ve bu durum onlar için aynı zamanda sosyal bir ihtiyaçtır (Lee, 2009). Ayrıca ergenler özellikle ergenlik döneminin özelliklerinden dolayı eleştirilmekten, küçük düşmekten ve hata yapmaktan da korkabilmektedirler (Mehtalia, \& Vankar, 2004). Bu durumda sosyal kayg1 sorunu ile karşı karşıya kalınabilir ve sosyal kaygı ergenler arasında daha sık rastlanabilen bir sorun olmaktadır (Tassin, Reynaert, Jacques \& Zdanowicz, 2014). Kashdan (2007) sosyal kaygıyı toplumsal bir davranışın gözlenmesine, incelenmesine ve değerlendirilmesine yönelik bir korku olarak tanımlamaktadır. Sosyal kaygı düzeyi yüksek bireyler sosyal ortamlardan uzaklaşmaya başlarlar ve sosyal ilişkileri bozulur (La Greca \& Lopezen, 1998; Stopa \& Clark, 2000).

Ergenlik dönemi sosyal kaygının görülme olasılığının yüksek olduğu dönemdir (Hamarta, 2009). Bu dönemde ergenler başkaları tarafından değerlendirilmekten korkarlar (Kashdan, 2007). Sosyal kaygı oldukça inatçı bir seyirde olabilmekte ve başka sorunlarla bir arada görülebilmekle beraber yapılan çalışmalar hem kadın hem erkek ergenlerde sosyal kaygının \%20 ve \%30 arasında en çok gözlenen problem olduğuna işaret etmektedir (Tassin ve D. 2014). Ergenlerde sosyal kayg1 ile birlikte alkol kullanımının, düşük akademik başarının, depresyon gibi ruh sağlığı problemlerinin, davranış problemlerinin ve psikotik semptomların görüldüğünü ortaya koyan araştırmalara rastlanmaktadır (Chhabra, Bhatia, Gupta, Kumar \& Srivastava, 2009; Cruz, Martins \& Diniz, 2017; Mehtalia \& Vankar, 2004; Pontillo, Guerrera, Ornella, Tata, Averna, Vicari \& Armando, 2017). Erkan, Güçray ve Çam (2002) çalışmasında koruyucu-istekçi ve otoriter ana-baba tutumuna sahip ergenlerin daha çok olumsuz değerlendirilmekten korktukları ve sosyal kaçınma düzeylerinin yüksek olduğu belirlenmiştir.

Sosyal kaygı düzeyi yüksek olan bireyler iletişimi başlatmaktan, devam ettirmekten, sosyal ortamlarda bulunmaktan kaçınırlar. Sosyal ortamlarda daha önce benzer bir durum yaşamamış olsalar bile sürekli diğerlerinin kendilerini değerlendireceklerini düşünürler ve bu durum endişelerini daha da artırır. Sosyal kaygısı yüksek kişiler utangaç tavırlarının yanı sıra ketum ve tedbirli davranırlar (Leary \& Hoyle, 2009). Ergenlerin özellikleri düşünüldüğünde içinde bulundukları dönemin etkisiyle olumsuz değerlendirilmekten daha çok çekinecekleri ve sosyal ortamlarda daha utangaç davranacakları söylenebilir.

Bireyin kendini değerlendirme biçimine göre ortaya çıkan öz-saygı da sosyal kayg1 ile ilişkili bir durumdur. Alan yazın incelendiğinde öz-saygı kavramının 'benlik tasarımı', 'benlik saygısı', 'öz kavram’ olarak isimlendirildiği görülmektedir. Eser’e (2005) göre özsaygi kişinin istekleri ile elde ettikleri arasındaki dengeyi ifade etmektedir. Kahriman'a (2002) göre ergenlerin arkadaş ortamında kabul görmesi, onaylanması onların öz- 
saygılarının artmasına neden olmaktadır. Yiğit'e (2010) göre öz-saygı düzeyi düşük olan ergenler kendilerine güven duymak konusunda sıkıntı yaşadıklarından sosyal ilişkiye girmekten de kaçınmaktadırlar. Ayrıca sosyal ortamdan çabuk etkilenip görüş ve inançlarını da çok çabuk değiştirebilmektedirler. Eriş ve İkiz (2013) çalışmalarında ergenlerin sosyal kaygı düzeyleri ile benlik saygıları arasında orta düzeyde negatif bir ilişki olduğunu ve cinsiyete göre sosyal kaygı ve benlik saygısı düzeylerinde anlamlı bir farklılık olmadığını belirlemişlerdir. Alan yazın incelendiğinde sosyal kaygı düzeyi yüksek bireylerin öz-saygı düzeylerinin düşük olduğunu ortaya koyan çalışmalara rastlanmaktadır (Eren-Gümüş, 2006; Erözkan, 2004; Gruber \& Heimberg, 1997; Leary, 2001). Bu çalışmalar göz önüne alındığında kendisini olumsuz şekilde değerlendiren öz-saygı düzeyi düşük ergenlerin sosyal ortamlarda olumsuz olarak eleştirilmekten korktukları ve kaygı yaşadıkları söylenebilir. Ayrica ergenler sosyal ortamlarda kendilerini akranlarnyla kıyaslayarak değerlendirmektedirler.

Wolpe ve Lazarus'a göre bireyin kendi duygularını, düşüncelerini ve haklarını uygun şekilde ifade edebilmesi güvengenlik -assertiveness- olarak tanımlanmaktadır. Alan yazın incelendiğinde "assertiveness" kavramının önceleri atılganlık olarak kullanıldığ 1 çalışmalara rastlanmaktadır. Ancak 1980'li yıllardan itibaren güvengen kavramının daha uygun olduğu belirtilmiş (Voltan-Acar, 1995) ve bu çalışmada da güvengenlik kavramı kullanılmıştır. Voltan-Acar'a (2007) göre güvengen bireyler başkalarının haklarına saygı duyarak kendi düşüncelerini ifade edebilen bireylerdir. Bu bireyler her ortamda olumlu ve olumsuz kendi düşüncelerini ve duygularını belirtmekten kaçınmazlar. Güvengenlik saldırganlık anlamına gelmez, etkili iletişim kurmanın bir şeklidir. Voltan-Acar, Arıcıŏlu, Gültekin ve Gençtanırım (2008) çalışmalarında güvengenliğin cinsiyet açısından anlamlı farklılık göstermediğini ve demokratik anne-baba tutumuna sahip bireylerin daha güvengen olduklarını belirlemişlerdir. Çalışmalar incelendiğinde güvengenliğin ayrılık anksiyetesi (Aslan, 2013); psikolojik iyi oluş ve benlik saygısı (Sarkova, Sleskova, Orosova, Geckova, Katreniakova, Klein Heuvel \& Dijk, 2013); öz-yeterlik (Parto, 2011) ile anlamlı ilişkisinin olduğunu belirten araştırmalar bulunmaktadır. Alan yazında güvengenlik konusundaki çalışmaların özellikle ergenler üzerinde yoğunlaştığ 1 fark edilmektedir. Sosyal kaygı düzeyi düşük ve öz-saygı düzeyi yüksek olan ergenler daha bağımsız davranarak daha güvengen davranışlar sergilemektedirler. Shanmugam ve Kathyayini’ye (2017) göre güvengenlik ve benlik saygısı herhangi bir psikolojik rahatsızlık duymadan ergenlerin farklı ortamlarda kendilerini ifade etmeleri için önemli araçlardır. Ayrıca benlik saygısı ve güvengen olma gibi özellikler ergenlerin sosyal ilişkilerini de desteklemektedir.

Ergenlik dönemi yetişkinliğe hazırlık dönemi olduğu gibi önemli gelişimsel deneyimlerin de yaşandığı bir dönemdir. Ergenler bu dönemde fiziksel ve cinsel açıdan olgunlaşmaya başladıkları gibi kişisel bağımsızlıklarını kazanmaya ve yetişkin rolleri kazanmak adına gerekli beceriler edinmeye çalışırlar. Bununla birlikte bu dönemde ergenler yetersiz olma duygularıyla başa çıkmaya çalışırlar ancak olumsuz düşüncelerden de çok kolay etkilenirler (Bhende, 1994; Townsend, 2012). Çalışmalar ergenlik döneminde sosyal kaygının çok sık rastlanan bir durum olduğunu ve sosyal kaygıya pek çok sorunun eşlik ettiğini göstermektedir(Tassin, Reynaert, Jacques \& Zdanowicz, 2014). Ayrıca ergenlerin sağlıklı iletişim kurabilmeleri için yüksek öz-saygının ve güvengenliğin de (Shanmugam \& Kathyayini, 2017) önemli özellikler olduğu vurgulanmaktadır. Bu araştırmanın amacı ergenlerin sosyal kaygı düzeyleri ile benlik saygıları ve güvengenlik düzeyleri arasındaki ilişkiyi incelemektedir. Ergen sağlı̆̆ının oldukça vurgulandığı ve önemsendiği bu dönemde 
bu çalışmanın sonuçlarının eğitimcilere, alanda çalışan psikolojik danışmanlara, ebeveynlere ve araştırmacılara ergenlik dönemini ve ergenlerin özelliklerini anlamada, sinıfta istenmeyen davranışların yönetiminde ve sebeplerinin -analizinde katkı sunacağı düşünülmektedir.

\section{Araştırmanın Yöntemi}

$\mathrm{Bu}$ çalışma ergenlerin sosyal kaygılarını öz-saygı ve güvengenlik açısından yordamaya yönelik ilişkisel modelde bir çalışmadır. İlişskisel modelde değişkenler arasındaki ilişkileri sebep sonuç bağı kurmaksızın, belirlemek amaçlanmaktadır (Fraenkel \& Wallen, 2006).

\section{1 Çalışma Grubu}

Araştırmanın çalışma grubunu yaşları 14 ile 18 arasında değişen 229 kadın (\%62) ve 140 erkek (\%38) olmak üzere toplam 369 lise öğrencisi oluşturmaktadır. Çalışma grubunda yer alan öğrenciler Türkiye'nin doğu bölgesinde yer alan liselere devam eden öğrencilerdir. Bu öğrencilerin 123'ü 9. sınıfa, 125'i 10. sınıfa ve 120'si 11. sınıfa devam etmektedir. Lise son sınıf ögrencileri üniversite sınavına hazırlanmalarından dolayı kaygı düzeyi yüksek olacağından araştırma kapsamına alınmamıştır.

\subsection{Veri Toplama Araçları}

\subsubsection{Ergenler İçin Sosyal Kaygı Ölçeği (ESKÖ)}

Greca (1999) tarafından geliştirilen ölçek Aydın ve Sütçü (2007) tarafından Türk Kültürüne uyarlanmıştır. Ölçek, 18 maddeden ve "olumsuz değerlendirilme korkusu (ODK)", "genel durumlarda sosyal kaçınma-huzursuzluk duyma (G-SKHD)" ve "yeni durumlardan sosyal kaçınma-huzursuzluk duyma (Y-SKHD)" olmak üzere üç alt boyuttan oluşmaktadır. Ölçeğin toplam puanı ile ODK alt ölçeği arasında .89; G-SKHD alt ölçeği arasında .75 ve Y-SKDH alt ölçeği arasında .85 düzeyinde anlamlı ilişki bulunmaktadır. Ergen Sosyal Kaygı Ölçeğinin (ESKÖ) güvenirlik çalışmasında Cronbach alfa iç tutarlık katsayısı .88 ve iki yarım güvenirlik katsayısı .85 bulunmuştur. Ölçeğin geçerlik çalışması için Çapa Çocuk ve Ergenler için Sosyal Fobi Ölçeği ile .77 ve Çocuklar için Durumluk Sürekli Kaygı Envanteri ile .66 düzeyinde ilişki olduğu belirlenmiştir.

\subsubsection{Coopersmith Öz-Saygı Envanteri Kısa Formu}

Öğrencilerin öz-saygı düzeyleri, orijinali 1967 yılında Coopersmith tarafindan geliştirilen 25 maddelik "Coopersmith Benlik Saygısı Envanteri" kısa formu ile elde edilmiştir. Ölçeğin Türkiye de bir çok defa geçerlik ve güvenirlik çalışmalarının yapıldığı görülmektedir (Aksoy, 1992; Pişkin 1996). Coopersmith tarafından geliştirilen bu ölçek, özsayg1 ile ilgili kendini küçümseme, liderlik popülerlik, anne-baba-aile, atılganlık ve kayg1 faktörlerini ölçmeye yönelik 25 maddeden oluşmaktadır. Ölçeğin güvenirlik çalışmasında Cronbach alfa iç tutarlılık katsayısı .86, benzer ölçekler geçerliği ise .60 olarak bulunmuştur (Pişkin, 1996). Güvenirlik çalışmasında Coopersmith aracın test-tekrar test güvenirlik katsayısını beş hafta arayla uygulaması sonucunda .88 , üç yıl arayla uygulaması sonucunda 
ise .70 bulmuştur. Türkiye de yapılan güvenirlik çalışmalarında Pişkin (1996), envanterin kısa formunun KR-20 sonucunda elde edilen güvenirlik katsayısını .76 olarak bulmuştur. Aksoy (1992) tarafindan "benzer ölçek geçerliği" yöntemiyle yapılan geçerlik çalışması sonucunda Baymur' un geliştirdiği "Benlik Tasarımı Envanteri” arasında yüksek ilişki ( $r=$ $.65, p<.05)$ bulmuştur.

\subsubsection{Kendini Belirleme Ölçeği}

Bireylerin güvengenlik düzeylerinin ölçülmesi için Voltan-Acar ve Öğretmen (2007) tarafindan geliştirilmiş olan Kendini Belirleme Ölçeği kullanılmıştır. Ölçekte güvengenlik alt boyutu için 11 ve çekingenlik alt boyutu için 17 olmak üzere 28 madde bulunmaktadır. Altılı likert şeklinde dizayn edilmiştir. Ölçekten alınan puanlar 28-168 aralığındadır ve puanlar arttıkça güvengenlik düzeyi artmaktadır. İç tutarlılık katsayısı çekingenlik alt boyutu için .83 ve güvengenlik alt boyutu için .78 olarak hesaplanmıştır. Test tekrar test güvenirlik katsayısı ise .78 olarak belirlenmiştir.

\subsection{Veri Analizleri}

Araştırmanın bağımlı değişkeni sosyal kaygı, bağımsız değişkeni öz-saygı ve güvengenliktir. Veri analizi öncesi eksik girildiği fark edilen sekiz veri ile anlamlı $\mathrm{Z}$ tablo değerleri kontrol edilerek +3 ve -3 'ü geçen yedi veri, veri setinden çıkarılmıştır. Ardından değişkenler arasında doğrusal ilişki olup olmadığı saçılma diyagramı ile incelenmiştir. Verilerin normal dağıldığı anlaşıldıktan sonra modelde otokorelasyonu test etmek için Durbin Watson değerine bakılmıştır. Durbin Watson değerinin 1.91 olduğu ve bu değer 1.5 ile 2.5 arasında olduğundan istenilen düzeyde olduğu (Kalayc1, 2006) belirlenmiştir. Çalışmada öncelikle Pearson korelasyon katsayıları ve ardından çoklu standart regresyon analizi tekniği sonuçları belirlenmiştir. Araştırmada anlamlılık düzeyi .05 olarak kabul edilmiştir.

\section{Bulgular}

Ergenlerin sosyal kaygı, öz-sayg1 ve güvengenlik puanlarının betimleyici istatistikleri ve korelasyon katsayıları Tablo 1'de verilmiştir.

Tablo 1. Değişkenler Arasındaki Korelasyon Katsayıları ve Değişkenlere İlişsin Betimsel İstatistikler

\begin{tabular}{llllllll}
\hline Değişkenler & 1 & 2 & 3 & 4 & $\begin{array}{l}\text { Güvenirlik } \\
(\alpha)\end{array}$ & $M$ & $S D$ \\
\hline 1.Sosyal Kayg1 & &. &. &. & 82 & 58.2 & 13.01 \\
2.Çekingen & $.637^{*}$ & &. &. & 80 & 58.57 & 15.62 \\
3.Güvengen & $-.222^{*}$ & $-.348^{*}$ & &. & 71 & 42.99 & 9.04 \\
4.Öz-Sayg1 & $-.433^{*}$ & $-.525^{*}$ & $.301^{*}$ & & 79 & 15.00 & 4.71 \\
\hline
\end{tabular}

$* * p<0.01$ 
Tablo 1 incelendiğinde bağımsız değişkenlerin birbiriyle ve bağımlı değişkenle .22 ve .64 arasında korelasyona sahip olduğu görülmektedir. Korelasyon değerleri çoklu bağlantı riski açısından .90'1 geçmemektedir (Çokluk, Şekercioğlu \& Büyüköztürk, 2012). Bu nedenle çoklu bağlantı problemi olmadığından regresyon analizine devam edilmiştir. Çekingenlik, güvengenlik ve öz-saygının lise öğrencilerinin sosyal kaygı düzeylerini yordayıp yordamadığını belirlemek için yapılan standart çoklu regresyon analizi sonuçları Tablo 2'de verilmiştir.

Tablo 2. Çekingenlik Güvengenlik ve Öz-Saygının Sosyal Kaygıyı Yordamasına İlişkin Çoklu Regresyon Analizi Sonuçları

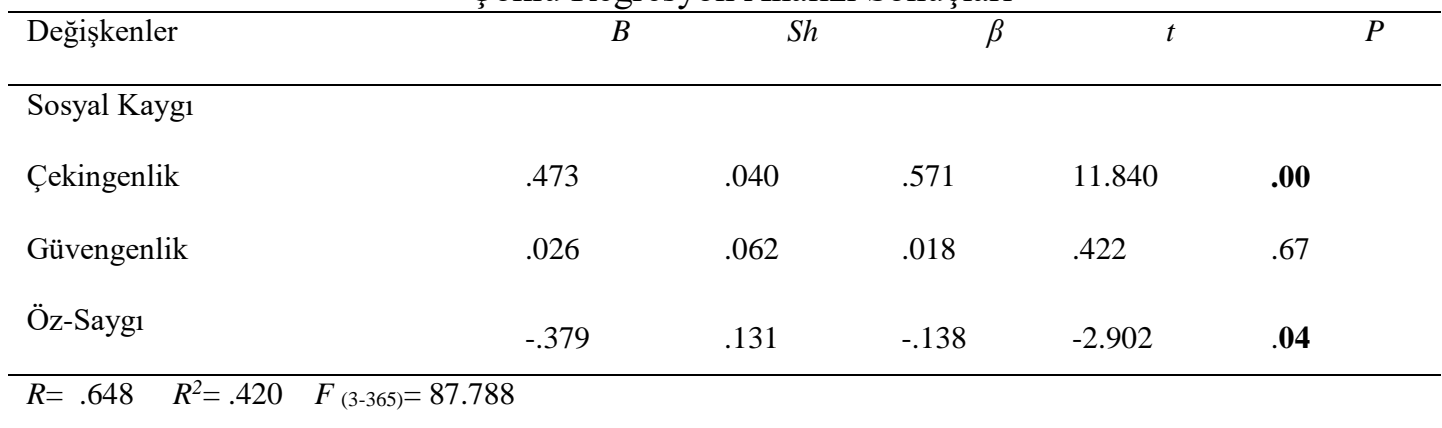

Tablo 2'ye göre, çekingenlik, güvengenlik, ve öz-saygı sosyal kaygının toplam varyansının \%42'sini $\left(R=.648, R^{2}=.420 \quad F(3-365)=87.788 \quad p<.01\right)$ açıklamaktadır. Regresyon katsayılarının anlamlılığına ilişkin t-testi sonuçları ise çekingenliğin $(t=11.840$, $p<.00)$ sosyal kaygıyı pozitif yönde; öz-saygının $(t=-2.902, p<.05)$ sosyal kaygıyı negatif yönde anlamlı olarak yordadığı görülmektedir. Ayrıca güvengenlik $(t=, 422)$ sosyal kaygıyı anlamlı olarak yordamamaktadır. Standardize edilmiş regresyon katsayılarına göre, sosyal kaygının anlamlı yordayıcıları önem sırasına göre: çekingenlik $(\beta=.578)$ ve öz-sayg1 ( $\beta=-.138)$ 'dir. Elde edilen bulguları özetlemek gerekirse çekingen olmak sosyal kaygıyı pozitif yönde, öz-saygı sosyal kaygıyı negatif yönde anlam lı olarak yordarken, güvengen olmak sosyal kaygıyı anlamlı olarak yordamamaktadır.

\section{Tartışma, Sonuç ve Öneriler}

Araştırmanın bulgularına bakıldığında ilk olarak, öz-saygı düzeyi yüksek olan ergenlerin sosyal kaygı düzeylerinin düşük olduğu görülmektedir. Öz-saygı düzeyi yüksek olan ergenlerin sosyal ilişkilerinde daha rahat ve güvenli olduğu bilinmektedir (Kuzgun, 2002). Ergenlerde sosyal kaygı özellikle sosyal işlevsellikte bozulma ve olumsuz benlik algısı gibi birçok probleme eşlik etmektedir. Farklı kültürlerde ve farklı popülasyonlarla yapılan çalışmalar ergenlikte benlik saygısının önemini vurgular. Benlik saygısı yüksek olan ergenler daha bağımsız sosyal yaşamın baskısı ile daha rahat başa çıkmaktadır. Sonuç olarak düşük ergenlerde benlik saygısının düşük olması daha zayıf kişilerarası ilişkilere ve sosyal durumlarda güven eksikliğine sebep olmaktadır (Ahmad, Bano, Ahmad \& Khanam, 2013; La Greca \& Lopezen, 1998). Alan yazın incelendiğinde sosyal kaygısı yüksek olan ergenlerin benlik saygılarının düşük olduğunu ortaya koyan çalışmalar (Eren-Gümüş, 2006; Eriş \& İkiz, 2013; Gruber \& Heimberg, 1997; Yousaf, 2015). Bu nedenlerden dolayı öz- 
saygısı düşük olan ergenlerin eleştirilme korkusu ile beraber sosyal ortamlarda daha kaygılı olmaları kaçınılmaz bir durum haline gelmektedir.

Araştırmanın bir diğer bulgusuna göre çekingen olan ergenlerin sosyal kaygısının da arttığı görülmektedir. Çekingen bireyler haklarını aramakta güçlük çekerler, hayır diyemezler, duygularını rahatlıkla ifade edemezler, etkili iletişim kurmakta güçlük çekerler ve genel anlamda kaygılıdırlar, ayrıca bu bireylerin sosyal beceri açısından da kendilerini yetersiz olarak algıladıkları görülmektedir (Mc Whirter \& Voltan-Acar, 2005; Voltan-Acar \& Öğretmen, 2007). Ergenlerdeki akran baskısı göz önüne alındığında güvengen olmak önemli bir sosyal beceridir. Sosyal kaygı kendini ifade edebilme becerisindeki yetersizliği içerir ve çekingen kişilerde sosyal kaygı artar. Çekingen olan kişiler konuşkan değildir ve başkaları tarafindan samimi olarak algılanmayabilirler. Bununla birlikte çekingen kişilerin daha yalnız algılandıkları da söylenebilir (Mofrad \& Mefradi, 2015). Çekingen kişilerin sosyal ilişkilerinde daha çok sosyal kaygı yaşadığını ortaya koyan çalışmalar bulunmaktadır (Delamater \& Mcnamara, 2001). Bu durumda sosyal kaygının azaltılmasında evde ebeveynlere ve sinıf içinde öğretmenlere daha demokratik yönetim stilleri benimsemeleri, tavsiye edilebilir, neticede çekingenlik ile anne babaların demokratik tutumları arasında ilişkinin söz konusu olduğu çalışmalara rastlanmaktadır (Voltan-Acar ve D., 2008).

$\mathrm{Bu}$ çalışma sadece araştırma verilerinin elde edildiği lise öğrencileri ile sınırlıdır. Benzer çalışmalar farklı öğretim kademelerinden öğrenciler ile gerçekleştirilebilir. Çalışmanın sonucuna göre çekingen olmak ergenlerin sosyal kaygı düzeylerini artırırken özsaygının yüksek olması sosyal kaygı düzeyini azaltmaktadır. Bundan dolayı ergenlerle çalışan okul psikolojik danışmanlarına sosyal kaygısı yüksek öğrencilerin çekingenliğini azaltacak ve öz-saygı düzeylerini artıracak eğitimler vermeleri önerilebilir. Bu konuda benzer şekilde ailelere ve öğretmenlere yönelik konsültasyon programlarının hazırlanması da uygun olacaktır. Özellikle öğretmenlere sınıf içerisinde öğrencilerin öğretim sürecine katılmalarının ve kendilerini başarılı hissetmelerinin sosyal kaygılarını azaltmak açısından da önemli olduğu vurgulanabilir, bu doğrultuda öğrencilerin başarı duygularını arttıracak nitelikte ve düzeyde etkinlikler düzenlemeleri tavsiye edilebilinir.

\section{Kaynaklar}

Aslan, S. (2013). Separation-individuation and assertiveness in late adolescents, Romanian Journal of Applied Psychology, 15(1), 27-32.

Ahmad, Z., R., Bano, N., Ahmad, R. \& Khanam, S., J. (2013). Social anxiety in adolescents: Does self-esteem matter?, Asian Journal of Social Sciences and Humanities, 2(2), 91-98.

Bhende, A.A. (1994) A study of sexuality of adolescent girls and boys in under privileged groups in Bombay. The Indian Journal of Social Work. LV (4), 557-571.

Chhabra, V., Bhatia, M.S., Gupta, S., Kumar, P. \& Srivastava, S. (2009). Prevalence of social phobia in school-going adolescents in an urban area. Delhi Psychiatry Journal, 12(1), 18-25.

Çokluk, Ö., Şekercioğlu, G., \& Büyüköztürk, Ş. (2012). Sosyal bilimler için çok değiş̧kenli istatistik: SPSS veLISREL uygulamaları. Pegem Akademi: Ankara

Cruz, E.L., Martins, P.D. \& Diniz, P.R. (2017). Factors related to the association of social anxiety disorder and alcohol use among adolescents: A systematic review. Journal de Pediatria, 93, 442-451. 
Eren-Gümüş, A. (2006). Sosyal kaygının benlik saygısına ve işlevsel olmayan tutumlara göre yordanması. Türk Psikolojik Danışma ve Rehberlik Dergisi, 26, 63-75.

Eriş, Y. \& İkiz, F.,E. (2013). Ergenlerin benlik saygısı ve sosyal kaygı düzeyleri arasındaki ilişki ve kişisel değişkenlerin etkileri, Turkish Studies, 8(6), 179-193.

Erkan, Z., Güçray, S. \& Çam, S. (2002) Ergenlerin sosyal kaygı düzeylerinin ana baba tutumları ve cinsiyet açısından incelenmesi. Çukurova Üniversitesi Sosyal Bilimler Dergisi, 10(10), 64-75.

Erözkan, A. (2004). Üniversite öğrencilerinin reddedilme duyarlılıkları ile sosyal kaygı düzeylerinin bazı değiş̧enlere göre incelenmesi. 13. Ulusal Eğitim Bilimleri Kurultayı. Malatya: İnönü Üniversitesi Eğitim Fakültesi.

Fraenkel, J.R., \& Wallen, N.E. (2006). How to design and evaluate research in education (6th ed.). Boston, MA: The McGraw-Hill Companies.

Gruber, K. \& Heimberg, R.G. (1997). A cognitive-behavioral treatment package for social anxiety. (Ed: Yalom, I.D. \& Walton, T.R.), Treating anxiety disorders. San Fransisco: Jossey-Bass Publishers.

Hamarta, E. (2009). Ergenlerin sosyal kaygılarının kişilerarası problem çözme ve mükemmeliyetçilik açısından incelenmesi. İlkögretim Online, 8(3).

Kahriman, G. (2002). Adölesanlarda aile ve arkadaǵlardan algılanan sosyal destek ile benlik saygısı iliş̧kisi. Yayımlanmamış Yüksek Lisans Tezi. Atatürk Üniversitesi, Sağlık Bilimleri Enstitüsü.

Kashdan, T., B. (2007). Social anxiety spectrum and diminished positive experiences: Theoretical synthesis and meta-analysis, Clinical Psychological Review, 27, 348-365

La Greca, A. M, \& Lopezen. (1998). Social anxiety among adolescent, Linkages with peer relations and friendships. Journal of Abnormal Psychology, 26, 83-94.

Leary, M.R (2001). Social anxiety as an early earning system: A refinement and extention of the self presentational theory. (Ed: Hofmann, S.G. \& DiBartolo, P.M.), From social anxiety to social phobia, multiple perspectives, (321-334) Boston: Allyn and Bacon.

Leary, M., R. \& Hoyle, R., H. (2009). Handbook of individual differences in social behaviour. London: The Guilford Press.

Lee, S. J. (2009). Online communication and adolescent social ties: Who benefits more from Internet use?. Journal of Computer-Mediated Communication, 14(3), 509-531.

McWhirter, J. \& Voltan-Acar, N. (2005). Çocukla iletişim. İstanbul: MEB Yayınları.

Mehtalia, K. \& Vankar, G., K. (2004). Social anxiety in adolescents, Indian Journal of Psychiatry, 46(3), 221-227.

Mofrad, S., K. \& Mehrabi, T. (2015). The role of self-efficacy and assertiveness in aggression among high-school students in Isfahan. Journal of Medicine and Life, 8 (4), 225-231.

Parto, M. (2011). Problem solving, self efficacy and mental health in adolescents: Assesing the mediating role of assertiveness. Social and Behavioral Sciences, 30, 644-648.

Pontillo, M., Guerrera, S., Ornella, S. Tata, M., C., Averna, R., Vicari, S. \& Armando, M. (2017). An overview of recent findings on social anxiety disorder in adolescents and young adults at clinical high risk for psychosis. Brain Sciences, 7(127), 2-9.

Sarkova, M., Sleskova, M., B., Orosova, O., Geckova, A., M., Katreniakova, Z., Klein D., Heuvel, W. \& Dijk, J., P. (2013). Associations between assertiveness, psychological well-being and self-esteem in adolescents. Journal of Applied Social Psychology, 43, 147-154.

Shanmugam, V. \& Kathyayini, B., V. (2017). Assertiveness and self-esteem in Indian adolescents. Galore Interantional Journal of Health Sciences and Research, 2(4), 8-13. 
Stopa, L., \& Clark, D. M. (2000). Social phobia and interpretation of social events. Behaviour research and therapy, 38(3), 273-283.

Tassin, C., Reynaert, C., Jacques, D. \& Zdanowicz, N. (2014). Anxiety disorders in adolescence. Psychiatria Danubina, 26(1), 27-30.

Townsend, M., C. (2012). Psychiatry mental health nursing. Seventh edition: Jaypee publications, 43-46).

Voltan-Acar, N.(1995). Psikolojik danışmada çeviri sorunu. Bilim ve Ütopya Dergisi, 14, 28 29.

Voltan-Acar, N. \& Öğretmen, T.(2007). Kendini belirleme(güvengenlik) ölçeği geliştirme çalışmaları. Türk Psikolojik Danışma ve Rehberlik Dergisi. 3(27), 67-78.

Voltan-Acar, N., Arıcıoğlu, A., Gültekin, F. \& Gençtanırım, D. (2008). Üniversite öğrencilerinin güvengenlik düzeylerinin incelenmesi, Hacettepe Üniversitesi Eğitim Fakültesi Dergisi, 35, 342-350.

Yiğit, H. (2010). Ergenlerin benlik saygılarının yaşam doyumu ve bazı özlük nitelikleri açısından incelenmesi. Yayımlanmamış yüksek lisans tezi, Selçuk Üniversitesi Eğitim Bilimleri Enstitüsü, Konya.

Yousaf, S. (2015). The relation betweeen self-esteem, parenting style and social anxiety in girls. Journal of Education and Practice, 6(1), 140-142. 